\title{
Potensi Biomasa Dan Karbon Pada Tegakan Hutan Mangrove Di Desa Tasik Malaya Kabupaten Kubu Raya
}

\author{
Widiya Octa Selfiany \\ Fakultas Pertanian Universitas Kapuas Sintang \\ Email: widiya211@gmail.com
}

\begin{abstract}
Abstrak: Penelitian ini bertujuan untuk memperoleh informasi tentang besarnya simpanan biomasa dan karbon pada hutan mangrove di Desa Tasik Malaya Kabupaten Kubu Raya. Analisis biomasa dan kandungan karbon pada tegakan hutan mangrove menggunakan metode survey dengan cara jalur berpetak. Peletakkan jalur dilakukan secara purposive sampling mulai dari pinggir pantai hingga mencapai daratan, dengan jumlah jalur yang dibuat sebanyak 5 jalur penelitian. Dari jalur tersebut dibuat sub-petak dengan ukuran $10 \mathrm{~m}$ x $10 \mathrm{~m}$ untuk tingkat pohon, dan $5 \mathrm{~m} \times 5 \mathrm{~m}$ untuk tingkat pancang. Hasil penelitian menunjukkan bahwa jumlah pancang sebesar 1.616 individu/ha, sedangkan jumlah pohon sebesar 302 individu/ha. Potensi biomasa pada tingkat pancang sebesar 31,94 ton/ha, sedangkan pada tingkat pohon sebesar 57,57 ton/ha. Potensi karbon pada tingkat pancang sebesar 15,97 ton $\mathrm{C} /$ ha atau setara dengan 58,46 ton $\mathrm{CO}_{2} /$ ha, sedangkan pada tingkat pohon potensi karbon sebesar 28,79 ton $\mathrm{C} / \mathrm{ha}$ atau setara dengan 105,36 ton $\mathrm{CO}_{2}$ /ha. Jumlah total simpanan karbon pada hutan mangrove Desa Tasik Malaya sebesar 44,76 ton C/ha atau setara dengan 163,81 ton $\mathrm{CO}_{2}$ /ha.
\end{abstract}

Kata Kunci : Biomassa, Karbon, Hutan Mangrove

\section{PENDAHULUAN}

Perubahan iklim global yang

terjadi akhir-akhir ini disebabkan karena terganggunya keseimbangan energi antara bumi dan atmosfir. Keseimbangan tersebut dipengaruhi antara lain oleh peningkatan gas-gas asam arang atau karbon dioksida $\left(\mathrm{CO}_{2}\right)$, metana $\left(\mathrm{CH}_{4}\right)$ dan nitrous oksida $\left(\mathrm{N}_{2} \mathrm{O}\right)$ yang lebih dikenal dengan gas rumah kaca (GRK). Saat ini konsentrasi GRK sudah mencapai tingkat yang membahayakan iklim bumi dan keseimbangan ekosistem (Hairiah dan Rahayu, 2007). Lugina et al,. (2011) menyebutkan disektor kehutanan, kontribusi terhadap GRK terutama disebabkan oleh gas karbon dioksida. Salah satu upaya untuk mencegah atau mengurangi peningkatan gas $\mathrm{CO}_{2} \mathrm{di}$ atmosfer adalah dengan mempertahankan keberadaan hutan dan menjaga keseimbangan ekosistem hutan. Hutan alami merupakan penyimpan karbon (C) tertinggi bila dibandingkan dengan sistem 
Potensi Biomasa Dan Karbon Pada Tegakan Hutan Mangrove

Di Desa Tasik Malaya Kabupaten Kubu Raya

penggunaan lahan, dikarenakan keragaman pohonnya yang tinggi, dan serasah dipermukaan tanah yang banyak (Hairiah dan Rahayu, 2007).

Tumbuhan memerlukan sinar matahari, gas karbondioksida $\left(\mathrm{CO}_{2}\right)$ yang diserap dari udara serta air dan hara yang diserap dari dalam tanah untuk kelangsungan hidupnya. Melalui proses fotosintesis, $\mathrm{CO}_{2}$ di udara diserap oleh tanaman dan diubah menjadi karbohidrat, kemudian disebarkan ke seluruh tubuh tanaman dan akhirnya ditimbun dalam tubuh tanaman berupa daun, batang, ranting, bunga, dan buah. Proses penimbunan C dalam tubuh tanaman hidup dinamakan proses sekuestrasi (karbon- sequestration). Dengan demikian mengukur jumlah karbon yang disimpan dalam tubuh tanaman hidup (biomasa) pada suatu lahan dapat menggambarkan banyaknya $\mathrm{CO}_{2}$ di atmosfer yang diserap tanaman (Hairiah dan Rahayu, 2007).

Desa Tasik Malaya Kecamatan Batu Ampar Kabupaten Kubu Raya memiliki hutan mangrove yang berpotensi dapat menyerap gas $\mathrm{CO}_{2}$ di atmosfer. Namun, informasi mengenai potensi biomasa dan karbon yang terdapat pada hutan mangrove di desa tersebut belum tersedia. Dengan demikian, penelitian mengenai estimasi karbon tersimpan pada tegakan hutan mangrove di Desa Tasik Malaya dirasa perlu dilakukan untuk mengetahui jumlah $\mathrm{CO}_{2}$ yang mampu diserap oleh vegetasi mangrove tersebut persatuan luas dan waktu, sehingga manfaat ekologi dari mangrove tersebut dapat diketahui, dimana konsentrasi gas $\mathrm{CO}_{2}$ di atmosfer semakin meningkat setiap tahunnya.

\section{METODE PENELITIAN}

Penelitian ini dilakukan selama dua minggu di lapangan. Metode yang digunakan dalam penelitian ini menggunakan metode survey dengan cara jalur berpetak. Pengumpulan data di lapangan menggunakan metode Non Destructive Sampling (pengambilan contoh tanpa pemanenan). Penentuan jalur contoh penelitian dilakukan dengan cara disengaja (Purposive Sampling). Peletakkan titik awal jalur penelitian diletakkan mulai dari 
tepi pantai hingga mencapai batas daratan. Jumlah jalur yang dibuat sebanyak 5 jalur penelitian. Jalur yang dibuat dalam penelitian ini dengan lebar 10 meter (5 m ke kiri 5 m ke kanan). Sub-petak contoh yang dibuat: (i) pohon; diameter $10 \mathrm{~cm}$ atau lebih, dengan ukuran sub-petak 10 meter x 10 meter; (ii) pancang; diameter kurang dari $10 \mathrm{~cm}$ sampai dengan tinggi 1,5 meter, dengan ukuran sup-petak 5 meter x 5 meter.

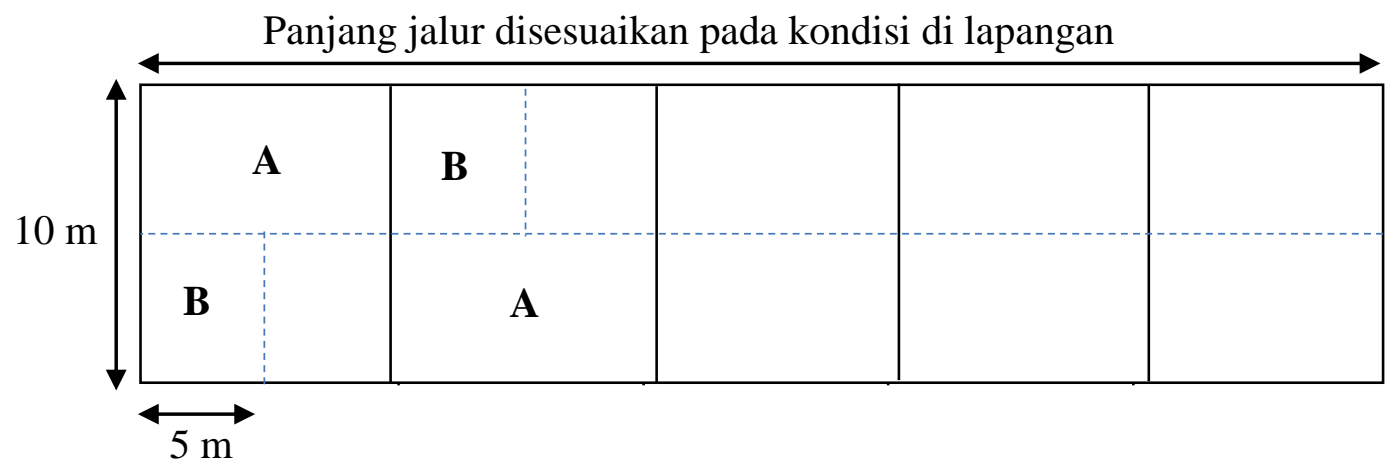

Gambar 1. Desain petak contoh di lapangan dengan metode jalur berpetak

Keterangan:

Petak $A=$ petak berukuran $10 \mathrm{~m} \times 10 \mathrm{~m}$ untuk pengamatan tingkat pohon Petak $\mathrm{B}=$ petak berukuran $5 \mathrm{~m} \times 5 \mathrm{~m}$ untuk pengamatan tingkat pancang

Data hasil penelitian ini berupa mengetahui biomasa dengan diameter dan jenis pohon, menggunakan persamaan allometrik selanjutnya dianalisa untuk sebagai berikut:

Tabel1. Persamaan allometrik yang digunakan

\begin{tabular}{|c|c|c|c|}
\hline Spesies & Persamaan Allometrik & $\varnothing(\mathrm{cm})$ & Sumber \\
\hline $\begin{array}{l}\text { Rhizophora } \\
\text { mucronata }\end{array}$ & $\mathrm{Y}=0,1466(\mathrm{DBH})^{2,3136}$ & $\mathrm{D}=5-33$ & Dharmawan (2010) \\
\hline $\begin{array}{l}\text { Avicennia } \\
\text { marina }\end{array}$ & $\mathrm{Y}=0,2905 \mathrm{DBH}^{2.2598}$ & $\begin{array}{l}\mathrm{D}=6,4- \\
35,2\end{array}$ & Dharmawan dan Siregar (2008) \\
\hline $\begin{array}{l}\text { Rhizophora } \\
\text { Apiculata }\end{array}$ & $\mathrm{W}_{\text {top }}=0,235 \mathrm{DBH}^{2.42}$ & $\mathrm{D}_{\max }=28$ & $\begin{array}{l}\text { Ong et al,. (2004) dalam } \\
\text { Komiyama et al,. (2007) }\end{array}$ \\
\hline Sonneratia spp & $\mathrm{W}_{\text {top }}=\rho^{*} 0,1848 \mathrm{DBH}^{2.3524}$ & & Dharmawan et al,. (2008) \\
\hline $\begin{array}{l}\text { Persamaan } \\
\text { Umum }\end{array}$ & $\mathrm{W}_{\text {top }}=0,251 \rho \mathrm{DBH}^{2.46}$ & $\mathrm{D}_{\max }=49$ & Komiyama et al,. (2005) \\
\hline
\end{tabular}

Keterangan : $\mathrm{Y}=$ Biomassa di atas permukaan tanah $(\mathrm{kg})$; Wtop : Biomassa di atas permukaan tanah $(\mathrm{kg}) ; \mathrm{DBH}=$ Diameter Breast Height, diameter setinggi dada atau 1,3 meter di atas permukaan tanah. 
Setelah diketahui nilai biomasanya kemudian dilakukan penghitungan nilai karbon tersimpan menggunakan rumus sebagai berikut:

\section{Karbon kayu $=\%$ Karbon $\mathbf{x}$ B}

Keterangan:

$$
\begin{aligned}
\% \text { Karbon }= & \text { Persentase karbon } \\
& \text { suatu jenis kayu } \\
\mathrm{B}= & \text { Biomasa }
\end{aligned}
$$

Dari keseluruhan karbon hutan, sekitar $50 \%$ diantaranya tersimpan dalam vegetasi hutan (Sutaryo, 2009).

Menghitung penyetaraan stok $\mathrm{C}$ ke $\mathrm{CO}_{2}$ menggunakan rumus berikut:

Serapan $\mathrm{CO}_{2}=$ $\underline{\mathrm{MrCO}_{2}} \times$ Kandungan $\mathrm{C}$

Ar. C

Keterangan :

$\mathrm{MrCO}_{2}=$ Berat molekul senyawa atom (44)

Ar. $\mathrm{C}=$ Berat molekul relatif atom (12)

\section{HASIL DAN PEMBAHASAN}

\section{A. Potensi Biomasa}

Biomasa pohon pada lokasi penelitian diklasifikasikan berdasarkan tingkat pertumbuhan, yaitu biomasa pohon $(\varnothing 10 \mathrm{~cm}$ sampai lebih) dengan ukuran subpetak penelitian $10 \mathrm{~m} \times 10 \mathrm{~m}$ atau luas $100 \mathrm{~m}^{2}$ dan biomasa pancang $(\varnothing$ $<10 \mathrm{~cm}$ sampai dengan tinggi 1,5 meter) dengan ukuran sub-petak $5 \mathrm{~m}$ x $5 \mathrm{~m}$ atau luas $25 \mathrm{~m}^{2}$. Biomasa ini dihitung dari keseluruhan sub-petak penelitian pada masing-masing tingkat pertumbuhan yang terdapat dalam jalur pengamatan. Dari keseluruhan sub-petak penelitian tersebut terdapat dua kelas tingkat pertumbuhan yang diukur di lapangan. Adapun hasil rekapitulasinya dapat dilihat pada Tabel 2.

Tabel 2. Kandungan Biomasa pada Tiap Tingkat Pertumbuhan Pohon

\begin{tabular}{llll}
\hline No & Tingkat Pertumbuhan & Jumlah Individu/Ha & Jumlah Biomasa (Ton/Ha) \\
\hline 1 & Pancang & 1.616 & 31,94 \\
2 & Pohon & 302 & 57,57 \\
Total Jumlah (Ton/Ha) & $\mathbf{1 . 9 1 8}$ & $\mathbf{8 9 , 5 1}$ \\
\hline
\end{tabular}

Sumber : Hasil Survey Lapangan di Desa Tasik Malaya Tahun 2019 
Potensi Biomasa Dan Karbon Pada Tegakan Hutan Mangrove

Di Desa Tasik Malaya Kabupaten Kubu Raya

Tabel 2 menunjukkan adanya perbedaan nilai biomasa pada tingkat pertumbuhan yang berbeda. Nilai biomasa tertinggi terdapat pada tingkat pertumbuhan pohon dengan jumlah kandungan biomasa sebesar 57,57 ton/ha. Sedangkan kandungan biomasa pada tingkat pertumbuhan pancang sebesar 31,94 ton/ha. Terdapat jumlah selisih yang cukup signifikan antara kedua tingkat pertumbuhan tersebut, yaitu sebesar 25,63 ton/ha.

Perbedaan biomasa ini terjadi dikarenakan adanya perbedaan kelas diameter pohon pada masing-masing tingkat pertumbuhan. Hal ini sejalan dengan pendapat Kusmana et al. (1992) menyatakan bahwa, besarnya biomasa ditentukan oleh diameter dan tinggi tanaman. Lebih lanjut Hardiansyah (2011) menyatakan bahwa kandungan biomasa tanaman juga akan dipengaruhi oleh besarnya tingkat kerapatan kayu. Tingkat kerapatan kayu merupakan nilai yang menunjukkan ukuran berat kayu dengan volume kayu. Semakin besar tingkat kerapatan kayu berarti semakin besar potensi biomasa, karena makin tinggi kerapatan kayu maka zat penyusun sel-sel tanaman semakin besar.

\section{B. Potensi Karbon Tegakan}

Setelah diperoleh nilai kandungan biomasa dari tiap tingkat pertumbuhan pohon, maka selanjutnya dari perolehan nilai biomasa tersebut dapat dilakukan penghitungan untuk mendapatkan kandungan karbon tersimpan. Penghitungan nilai karbon tersimpan dilakukan menurut Sutaryo (2009) dari keseluruhan karbon hutan, sekitar $50 \%$ diantaranya tersimpan dalam vegetasi hutan. Sehingga apabila dikalikan dengan kandungan biomasa pada tiap kelas tingkat pertumbuhan, maka akan diperoleh hasil yang dapat dilihat pada Tabel 3 . 
Tabel 3. Nilai Kandungan Karbon Tersimpan pada Masing-masing Tingkat Pertumbuhan

\begin{tabular}{|c|c|c|c|c|c|}
\hline No & $\begin{array}{l}\text { Tingkat } \\
\text { Pertumbuhan }\end{array}$ & $\begin{array}{l}\text { Jumlah } \\
\text { Individu/Ha }\end{array}$ & $\begin{array}{l}\text { Jumlah Biomasa } \\
\text { (Ton/Ha) }\end{array}$ & $\begin{array}{l}\text { Jumlah Karbon } \\
\text { (Ton/Ha) }\end{array}$ & $\begin{array}{l}\text { Penyetaraan } \\
\text { Stok C ke CO } \\
\left.\text { (Ton } \mathrm{CO}_{2} / \mathrm{Ha}_{2}\right)\end{array}$ \\
\hline 1 & Pancang & 1.616 & 31,94 & 15,97 & 58,46 \\
\hline 2 & Pohon & 302 & 57,57 & 28,79 & 105,36 \\
\hline \multicolumn{2}{|c|}{ Total Jumlah } & 1.834 & 1.918 & 44,76 & 163,81 \\
\hline
\end{tabular}

Sumber : Hasil Survey Lapangan di Desa Tasik Malaya Tahun 2019

Tabel 3 dapat dilihat bahwa potensi karbon tersimpan tertinggi terdapat pada tingkat pertumbuhan pohon dengan jumlah kandungan karbon sebesar 28,79 ton $\mathrm{C} / \mathrm{ha}$ atau setara dengan 105,36 ton $\mathrm{CO}_{2} /$ ha. Sedangkan pada tingkat pertumbuhan pancang nilai kandungan karbon sebesar 15,97 ton $\mathrm{C} /$ ha atau setara dengan 58,46 ton $\mathrm{CO}_{2} /$ ha. Jumlah potensi karbon tegakan hutan mangrove di Desa Tasik Malaya sebesar 44,76 ton C/ha atau setara dengan 163,81 ton $\mathrm{CO}_{2} /$ ha.

Hasil yang diperoleh penulis, kemudian jika dibandingkan dengan hasil penelitian Mulyadi et al (2017), dimana hasil penelitian yang diperoleh Mulyadi et al (2017) sebesar 26,63 ton C/ha. Maka terdapat perbedaan nilai karbon yang diperoleh penulis dengan Mulyadi et al (2017), perbedaan tersebut sebesar 18,13 ton $\mathrm{C} / \mathrm{ha}$. Hasil yang diperoleh penulis lebih besar dari pada hasil penelitian Mulyadi et al (2017). Hal ini bisa saja terjadi karena pada lokasi penelitian Mulyadi et al (2017) jumlah pohon yang terdapat di dalamnya memang jauh lebih kecil jika dibandingkan dengan lokasi penelitian penulis.

Hasil yang diperoleh penulis sudah memasuki batas ambang minimun hutan mangrove sekunder ditingkat nasional. Dimana batas ambang minimun karbon tegakan di hutan mangrove sekunder tingkat nasional yang ditetapkan oleh Rochmayanto et al,. (2014) adalah sebesar 37,03 ton C/ha. Guna lebih jelasnya dapat dilihat pada Tabel 4. 
Potensi Biomasa Dan Karbon Pada Tegakan Hutan Mangrove

Di Desa Tasik Malaya Kabupaten Kubu Raya

Tabel 4. Cadangan Karbon pada Berbagai Tipe Hutan Tingkat Nasional

\begin{tabular}{lllllllll}
\hline $\begin{array}{l}\text { Tipe Tutupan } \\
\text { Lahan }\end{array}$ & $\begin{array}{l}\text { Nilai } \\
\text { Minimum } \\
\text { (Ton/Ha) }\end{array}$ & $\begin{array}{l}\text { Nilai } \\
\text { Maksimum } \\
\text { (Ton/Ha) }\end{array}$ & $\begin{array}{l}\text { Median } \\
\text { (Ton/Ha) }\end{array}$ & $\begin{array}{l}\text { Rerata } \\
\text { (Ton/Ha) }\end{array}$ & N & Sd & Se & Keterangan \\
\hline $\begin{array}{l}\text { Hutan lahan } \\
\text { kering primer }\end{array}$ & 64,21 & 323,171 & 178,4 & 176,1 & 25 & 80,79 & $16,16 \begin{array}{l}\text { Dihitung dari } \\
\text { berbagai } \\
\text { sumber }\end{array}$ \\
$\begin{array}{l}\text { Hutan lahan } \\
\text { kering sekunder }\end{array}$ & 34,99 & 216,85 & 87,43 & 103,59 & 29 & 52,79 & 9,8 & $\begin{array}{l}\text { Dihitung dari } \\
\text { berbagai } \\
\text { sumber }\end{array}$ \\
$\begin{array}{l}\text { Hutan gambut } \\
\text { primer }\end{array}$ & 56,54 & 200,23 & 113,33 & 123,67 & 8 & 56,02 & 19,81 & $\begin{array}{l}\text { Dihitung dari } \\
\text { berbagai } \\
\text { sumber }\end{array}$ \\
$\begin{array}{l}\text { Hutan gambut } \\
\text { sekunder }\end{array}$ & 37,51 & 142,07 & 92,32 & 10,26 & 13 & 37,14 & 10,3 & $\begin{array}{l}\text { Dihitung dari } \\
\text { berbagai } \\
\text { sumber } \\
\text { Dihitung dari } \\
\text { berbagai } \\
\text { sumber }\end{array}$ \\
$\begin{array}{l}\text { Hutan } \\
\text { mangrove } \\
\text { primer }\end{array}$ & 41,8 & 393,62 & 162 & 188,3 & 5 & 133,18 & 59,56 \\
$\begin{array}{l}\text { Hutan } \\
\text { mangrove } \\
\text { sekunder }\end{array}$ & 37,03 & 142,9 & 92,14 & 94,07 & 10 & 45,06 & 14,25 & $\begin{array}{l}\text { Dihitung dari } \\
\text { berbagai } \\
\text { sumber }\end{array}$ \\
$\begin{array}{l}\text { Hutan tanaman } \\
\text { Dihitung dari } \\
\text { berbagai } \\
\text { sumber }\end{array}$ \\
\hline
\end{tabular}

Sumber : Rochmayanto et al. (2014)

Keterangan : N : Jumlah data; Sd : Standar deviasi; SE : Standar eror

Jika dilihat dari batas ambang minimum jumlah karbon tegakan pada hutan mangrove sekunder yang ditetapkan oleh Rohmayanto et al,. (2014) terdapat selisih antara hasil yang diperoleh penulis dengan Rohmayanto et al,. (2014), dimana hasil yang diperoleh penulis lebih besar jika dibandingkan dengan batas ambang mimimum Rohmayanto et al,. (2014) sebesar 7,73 ton C/ha. Menurut Herianto dan Subiandono (2012), kandungan karbon pada tanaman menggambarkan berapa besar tanaman tersebut dapat mengikat $\mathrm{CO}_{2}$ dari udara. Sebagian karbon akan menjadi energi untuk proses fisiologi tanaman dan sebagian masuk ke dalam struktur tumbuhan dan menjadi bagian dari tumbuhan, misalnya selulosa yang tersimpan pada batang, akar, ranting dan daun.

\section{PENUTUP}

\section{Kesimpulan}

Dari hasil penelitian dan uraian pembahasan serta tujuan dan manfaat penelitian, maka dapat ditarik kesimpulan sebagai berikut: 
1) Potensi biomasa pada tingkat pertumbuhan pancang sebesar 31,94 ton/ha, sedangkan pada tingkat pertumbuhan pohon sebesar 57,57 ton/ha.

2) Potensi karbon tersimpan pada tingkat pertumbuhan pacang sebesar 15,97 ton $\mathrm{C} /$ ha atau setara dengan 58,46 ton $\mathrm{CO}_{2} /$ ha, sedangkan pada tingkat pohon potensi karbon sebesar 28,79 ton $\mathrm{C} /$ ha atau setara dengan 105,36 ton $\mathrm{CO}_{2} / \mathrm{ha}$.

3) Jumlah total potensi karbon tersimpan pada hutan mangrove di Desa Tasik Malaya Kecamatan Batu Ampar kabupaten Kubu Raya adalah sebesar 44,76 ton $\mathrm{C} / \mathrm{ha}$ atau setara dengan 163,81 ton $\mathrm{CO}_{2} /$ ha.

\section{Saran}

1) Diharapkan penelitian ini dapat memberikan informasi kepada masyarakat mengenai potensi karbon yang terkandung pada kawasan tersebut, sehingga dapat memotivasi masyarakat untuk lebih menjaga hutan.
Mengingat konsentrasi gas $\mathrm{CO}_{2}$ di atmosfer yang semakin meningkat setiap tahunnya.

2) Karbon tersimpan tidak hanya terdapat pada tegakan yang masih hidup saja, tetapi karbon juga tersimpan pada tumbuhan bawah, kayu mati, serasah, dan bahan organik tanah. Untuk mendapatkan jumlah simpanan karbon yang lengkap perlu dilakukan penelitian lanjutan untuk meneliti kandungan karbon pada tumbuhan bawah, kayu mati, serasah, dan bahan organik tanah pada hutan mangrove tersebut.

\section{DAFTAR PUSTAKA}

Dharmawan I.W.S, dan Siregar C.A. 2008. Karbon Tanah dan Pendugaan Karbon Tegakan Avicennia marina (Forsk.) Vierh. di Ciasem, Purwakarta. Jurnal Penelitian dan Konservasi Alam 5 (04) : 317328.

Dharmawan I.W.S. 2010. Pendugaan Biomasa Karbon Diiatas Permukaan Tanah Pada Tegakan Rhizophora mucronata Di Ciasem, Purwakarta. Jurnal Ilmu Pertanian Indonesia 15 (01) : 50-56. 
Potensi Biomasa Dan Karbon Pada Tegakan Hutan Mangrove

Di Desa Tasik Malaya Kabupaten Kubu Raya

Hairiah K, Rahayu S. 2007. Pengukuran 'Karbon Tersimpan' Di Berbagai Macam Penggunaan Lahan. Bogor. Word Agroforestry Centre.

Hardiansyah G. 2011. Potensi Pemanfaatan Sistem TPTII Untuk Mendukung Upaya Penurunan Emisi Dari Deforestasi dan Degradasi Hutan (REDD) (Studi Kasus Areal IUPHHK PT. Sari Bumi Kusuma di Kalimantan Tengah). Sekolah Pascasarjana. Institut Pertanian Bogor. Bogor.

Heriyanto, N.M, E. Subiandono. 2012. Komposisi Dan Struktur Tegakan, Biomasa, Dan Potensi Kandungan Karbon Hutan Mangrove Di Taman Nasional Alas Purwo. Jurnal Penelitian Hutan dan Konservasi Alam 9 (1) : 023032.

Komiyama A, Ong J.E, Poungparn S. 2007. Allometry, Biomass, and Productivity of Mangrove Forest: A review. 89: 128-137. doi:10.1016/j.aquabot.2007.12. 006.

Kusmana C, Sabiham S, Abe K, Watanabe H. 1992. An estimation of above ground tree biomass of a mangrove forest in East Sumatera. Jurnal Tropics. 1 (4):143 257.

Lugina M, Ginoga K.L, Wibowo A, Bainnaura A, Partiani T. 2011. Prosedur Operasi Standar (SOP) untuk Pengukuran dan Perhitungan Stok Karbon di Kawasan Konservasi.Pusat Penelitian dan Pengembangan Perubahan Iklim dan Kebijakan Badan Penelitian dan Pengembangan Kehutanan Kementerian Kehutanan, Republik Indonesia.

Mulyadi, D Astiani, TF Manurung. 2017. Potensi Karbon Pada Tegakan Hutan Mangrove di Desa Sebatuan Kabupaten Sambas. Jurnal Hutan Lestari 5 (03) : 592-598.

Rochmayanto Y, Wibowo A, Lugina M, Butarbutar T, Mulyadin R.M, Wicaksono D. 2014. Cadangan Karbon pada Berbagai Tipe Hutan dan jenis dan Jenis Tanaman di Indonesia (Seri 2).

Sutaryo D. 2009. Penghitungan Biomassa 'Sebuah Pengantar Untuk Studi Karbon dan Perdagangan Karbon' Wetlands International Indonesia Programme. 